\title{
Spillback Effects of Expansion When Product-Types and Firm-Types Differ
}

\author{
Will Mitchell \\ Kulwant Singh \\ University of Michigan
}

\begin{abstract}
Contrary to perspectives that credit firms with only limited abilities to undertake significant change successfully, recent research has demonstrated that firms often improve their performance after undertaking major expansion to their operations. In this paper, we build on a study by Mitchell and Singh (1993) to test for differences in expansion effects, depending on whether the new goods substitute for old products and whether the firm is a generalist or specialist participant in the industry. The analysis helps us understand when a business can undertake major change successfully. The results have implications for ecological and other definitions of the core of a business and highlight the necessity for firms to undertake changes even at considerable risk to their existing operations.
\end{abstract}

How readily should firms undertake major expansion to their core businesses? And what impact does such expansion have on their existing core activity? Several ecological studies (e.g., Hannan \& Freeman 1977, 1984, 1989; Miner, Amburgey \& Stearns, 1989) offer extensive argument and evidence that major organisational changes often result in reduced organisational performance. Other studies have found little impact of major change (e.g, Singh, House \& Tucker, 1986; Kelly \& Amburgey, 1989; Delacroix \& Swaminathan, 1991; Zajac \& Shortell, 1989), however, while some researchers have found that major changes are sometimes converted into successful growth or result in longer business survival (Haveman, 1992; Mitchell \& Singh, 1993). It is clear, therefore, that organisational change per se is not necessarily harmful. Rather, the impact varies by the nature of the change undertaken and by the depth of resources possessed by organisations. Therefore, identifying conditions that differentiate between positive and negative influences of expansion is an important research goal.

In this paper, we attempt to identify product and firm-type conditions under which organisational change can be beneficial to organisations. We build on Mitchell and Singh (1993) to address how expansion or non-expansion into new technical subfields within an industry affects market share and survival

Direct all correspondence to: Will Mitchell, University of Michigan, School of Business Administration, Ann Arbor, MI 48109-1234. Bitnet: <USERLGRY@umichum>. Internet: <Will. Mitchell@um.cc.umich.edu> 
performance in the firms' established businesses. While the earlier study controlled effects of firms' market and organisational strength on the success of expansion, the analysis did not evaluate the impact of new good substitutability and firms' existing product scope. Yet these factors are central issues in defining a firm's business and its capabilities and can be expected to influence the success with which firms undertake major expansion. We argue that cases in which new goods substitute for existing products will have different effects on expansion success than cases when the new goods are neutral with respect to the old. We also predict that firms offering several product lines, which we refer to as generalists, will experience different effects from expansion than specialist incumbents that only offer a single product line. We present several hypotheses and research questions concerning the interaction between these product-types and firm-types. In the analyses, we control for differences in firms' initial strength, which may influence their ability to undertake expansion. We test our predictions on the Mitchell and Singh (1993) data, the population of incumbents of the American market for medical diagnostic imaging equipment over a 35 year period.

\section{Spillback Effects On Established Businesses}

Industry incumbents face competing risks as new markets or technical subfields emerge. Failure to expand into these new fields may be perilous, depriving firms of the technical or market know-how and increased resource flows that may be required for continued success in a traditional business (Mitchell, 1989). Moreover, successful expansion into new fields within the industry can have many salutary effects on current operations (Mitchell \& Singh, 1993) or overall firm performance (Haveman, 1992). On the other hand, expansion into new parts of the industry may disrupt successful routines in an existing business, strain available resources, cause the organisation to loose its focus, and lead to business failure (Cyert \& March, 1963; Hannan \& Freeman, 1977, 1984; Nelson \& Winter, 1982).

We refer to the benefits that a firm enjoys in its base business as a result of undertaking an expansion into a new business as spillback benefits. Such benefits include economies of scale (Porter, 1980), scope (Teece, 1980), and learning (Amit, 1986). Product improvement opportunities resulting from serendipitous or designed improvements in R\&D (Nelson, 1959) and manufacturing capability (Wheelwright, 1985) for the new products often provide useful capabilities that benefit existing products. In addition, expansion into new subfields may provide organisational and financial advantages in the base operations through competition-induced improvements in efficiency (Leibenstein, 1966; Shelton, 1967). Enhancements made to structure and control systems to accommodate the expansion may benefit existing product lines.

The positive effects of expansion are likely to be strongest in the context of low-transilience innovation (Abernathy \& Clark, 1985), that is, innovation involving significant changes to the technology of core products but only incremental change to supporting assets such as reputations and distribution 
systems. Firms undertaking low-transilience expansion can build on their stock of supporting assets and are likely to face fewer resource and knowledge constraints in their new ventures (Teece, 1986). In addition, improvements and extensions of supporting assets needed for participation in the new product area will often be useful or necessary for the base business. The strains on existing activities are also likely to be less following low-transilience expansion, as organisations will usually need to make relatively few changes to supporting routines and activities (Romanelli \& Tushman, 1991). Such changes include developing or acquiring new technologies, new markets, new distribution channels, new resources, and new internal structures and procedures. Hence, expansion in low-transilience cases will often produce large benefits at relatively low cost.

Nonetheless, expansion also may create spillback disadvantages, even in low-transilience cases. Failure of a new business may cause managerial or financial problems for an existing business. Successful expansion may result in sales cannibalisation, organisational and market confusion, and diversion of material and managerial resources. The established businesses of expanding firms will sometimes suffer, therefore, while nonexpanding firms may continue to perform well (Cooper \& Schendel, 1976).

In the following sections, we discuss and analyze differences in products and firms that may lead to different business performance following expansion. We use several terms throughout the discussion. We define an industry as a group of firms that manufacture goods having "reasonable interchangeability of use or cross elasticity of demand" (U.S. Supreme Court, 1964, p. 76). A technical subfield of an industry (Mitchell, 1989) is a set of products that draw on a distinct knowledge base (Nelson \& Winter, 1982; Dosi, 1988). By incumbent, we mean a firm participating in the industry when a new technical subfield emerges. We refer to the subfield in which an incumbent operated when the new subfield emerged as its base subfield (or subfields) and its operations in the base subfield as its base business. We refer to the market share attained in its base subfield by an incumbent after the emergence of a new subfield as subsequent market share. A substitute subfield is a new subfield in which products tend to substitute for goods in an established subfield, while a neutral subfield is a new subfield in which products do not substitute substantially for goods in an established subfield. ${ }^{1}$ We define specialists as firms that operate in only one technical subfield of an industry and generalists as firms that participate in more than one technical subfield of that industry.

Two key conditions frame this research. First, we focus on low-transilience innovation. Second, we address cases in which established goods continue to be sold even after new technology is introduced. Both conditions are found in the medical diagnostic imaging industry and in many other cases of industry evolution. ${ }^{2}$

\section{Substitute Versus Neutral Products}

Most new goods introduced into an industry will at least partially substitute for established products, but some goods will substitute more directly than 
others. Mitchell (1989) found that industry incumbents are more likely to expand into a new subfield if the new products directly replace existing products. If a new product completely dominates the old, so that sales of the old good are almost eliminated, a firm that expands into the new subfield is likely to exit from the base subfield. When sales of the old products continue, although perhaps at a reduced rate, there may be spillback benefits of expansion into the substitute subfield that improve performance in the base subfield. These benefits may be gained from reputational spillback, increased understanding of customer demands, volume economies, and other supporting asset symmetry between the subfields.

An alternate hypothesis regarding expansion into substitute products is that sales cannibalisation and organisational limitations will lead to reduced performance of expanding firms rather than increased market share and longer survival in the base subfield, even when sales of the old products continue (Reinganum, 1983). However, we expect that the alternate logic will not apply when the established products continue to be sold at a significant level. Instead, continued base subfield sales in low-transilience conditions will enable firms that participate in the new subfield to spill benefits back into the older business.

Although expansion into neutral subfields may create some technical or production benefits, spillback benefits stemming from reputational, product, and market complementarity are likely to be less than for substitute products. Consequently, we expect expansion into neutral subfields to offer fewer benefits for performance in the base subfield relative to expansion into substitute subfields.

Proposition la. Incumbents expanding into substitute subfields will tend to prosper in their base businesses, while incumbents expanding into neutral subfields will gain few advantages.

Failure to expand into a substitute subfield will clearly be detrimental to firms when the substitute product eliminates sales in the base subfield. However, failure to expand even when base subfield sales continue at a significant level can harm performance by depriving firms of new technological and organisational skills and potential resource inflows. The benefits forgone are likely to be relatively few for neutral products, because these products have few product-market similarities with existing product lines. Consequently, failure to expand is likely to retard performance more for substitute than neutral products.

Proposition $1 b$. Incumbents that do not expand into substitute subfields will tend to suffer in their base businesses, while incumbents that do not expand into neutral subfields will realise few disadvantages.

\section{Specialist Versus Generalist Firms}

We expect specialist and generalist firms to face different expansionnonexpansion tradeoffs. Compared to specialists, generalists are likely to have 
more industry-related slack and greater industry-related resources with which to support existing and new operations (Hannan \& Freeman, 1977). Generalists are also likely to possess more organisational skills for expanding, having previously undertaken this process (Mitchell \& Singh, 1993). Specialists on the other hand, will need to develop new organisational skills even while expanding. Therefore, the stress created by expansion may be felt more strongly throughout the base business of a specialist.

We expect this stress to be felt whether a specialist is a one-industry singleproduct company or a multi-industry firm with operations in a single technical subfield of the expanding industry. Single-product firms will have few extraneous resources, while diversified companies will have few industry-related resources or experience to draw from if problems arise during expansion. The multi-industry diversified firm also may face problems of low corporate commitment and may simply divest if the expansion runs into unexpected problems.

As well as different expansion benefits and threats, specialists and generalists may face different threats if they do not expand. Generalist success typically stems from offering a broad range of products and a generalist firm risks reducing or losing reputational, distribution, and other advantages if it does not expand. In contrast, specialist success flows from focusing on a single set of products, so that the effects of not expanding into a new subfield are likely to be less severe if products in its focal subfield continue to be sold. ${ }^{3}$

Proposition 2a. Expanding generalists will tend to prosper in their base businesses, while expanding specialists will suffer.

Proposition 2b. Generalists that do not expand will tend to suffer in their base businesses, while specialists that do not expand will realise few disadvantages.

\section{Product-Type And Firm-Type Interactions}

We expect to find significant interactions between product-types and firmtypes. Expansion by a generalist into a substitute product area, for instance, may have different spillback effects from expansion by a specialist into the same product area. We will consider the eight possible three-way interactive categories that arise from our expansion-nonexpansion, substitute-neutral, and generalistspecialist classifications. Some interactive effects will be derived as hypotheses, while others will be presented as empirical research questions.

First, let us consider expansion by a generalist incumbent into a substitute subfield. Because Propositions $1 \mathrm{a}$ and $2 \mathrm{a}$ predict that expansion into substitute subfields and expansion by generalist firms both will lead to spillback benefits, we predict that the three-way interaction will be positive. Drawing from Propositions $1 \mathrm{~b}$ and $2 \mathrm{~b}$, we also predict that the effect of nonexpansion in such cases will be negative, owing to the lost technical and market opportunities. 
H1a. Generalists that expand into substitute subfields will achieve better performance in their base businesses.

H1b. Generalists that do not expand into substitute subfields will suffer poorer performance in their base businesses.

Second, we take up the case of expansion by a generalist incumbent into a neutral subfield. Propositions $2 \mathrm{a}$ and $2 \mathrm{~b}$ expect generalist expansion to be positive and non-expansion to be negative, while proposition la holds that expansion in the neutral case will provide few benefits. This implies that the combined effect for generalists is likely to be positive for expansion and negative for nonexpansion. The impact of the generalist-neutral combinations may be weaker than the generalist-substitute case, but we will leave that issue for empirical investigation. Propositions $2 \mathrm{~b}$ and $1 \mathrm{~b}$ produce a complementary nonexpansion hypothesis concerning generalists and neutral subfields.

H2a. Generalists that expand into neutral subfields will achieve better performance in their base businesses.

H2b. Generalists that do not expand into neutral subfields will achieve poorer performance in their base businesses.

Ihird, consider expansion by a specialist incumbent into a substitute subfield. Proposition la expects substitute expansion to be positive, but Proposition $2 \mathrm{a}$ predicts that the specialist expansion will be negative. The two effects may moderate each other, but our initial estimate is that the positive influence of expansion may dominate. If so, then the combined effect of expansion, product-type, and firm-type will be positive and the effect of nonexpansion in the same combination will be negative. We base this estimate on two factors. First, Mitchell and Singh (1993) identified strong positive spillbacks of expansion. Second, this paper examines specialist expansion between subfields within an industry, for which we expect negative spillback to be less than for cases in which expansion takes place across industries. Propositions $1 \mathrm{~b}$ and $2 \mathrm{~b}$ again produce a complementary nonexpansion hypothesis. Given the tradeoffs involved in specialist-substitute expansion, we expect this effect to be weaker than in the generalist-substitute case; we investigate this as an empirical question.

H3a. Specialists that expand into substitute subfields will achieve better performance in their base businesses.

H3b. Specialists that do not expand into substitute subfields will achieve poorer performance in their base businesses.

The final issue concerns expansion by specialist incumbents into neutral subfields. We predicted above that expansion by specialists and expansion into neutral subfields would generate few spillback benefits, because there are relatively few reputational, product, and market benefits that a specialist firm 
could gain from entering a subfield that does not substitute for its existing activities. We can raise no strong prior case for how the advantages and disadvantages of expansion will trade-off against the limited benefits gained from a specialist's expansion into a neutral subfield. Therefore, we present the effects of the expansion and nonexpansion for the combination of specialist firms and neutral subfields as research questions.

Research question 1a. Will specialists that expand into neutral subfields realise differential performance in their base businesses?

Research question $1 b$. Will specialists that do not expand into neutral subfields realise differential performance in their base businesses?

\section{Methods}

\section{Data}

We examine the performance of firms operating in four base subfields of the medical diagnostic imaging industry between 1953 and 1989. The study period commences one year before the emergence of the second technical subfield of the industry (nuclear medicine in 1954) to allow the identification of incumbent firms in the industry, and covers the emergence of all new technical subfields in the industry. This industry consists of firms that manufacture equipment used by physicians and other health care workers to nonintrusively examine organs and physiological activity within live beings. Table 1 lists new technical subfields of the imaging industry that have emerged since the early 1950s to substitute for and complement earlier x-ray imaging products. Despite the introduction of the new products, sales of the established devices in the base subfields continue to be significant, as shown in Figure 1.

In defining the sample and collecting data, we omitted component suppliers, treated the U.S. market as the geographic limit, used calendar years as the measure of participation, and dated expansion as the year in which a firm began to manufacture imaging systems in the new subfield. All firms manufactured equipment for the human medical diagnostic field. We conducted the analysis at the parent-firm level for the industry, owing both to difficulty in assigning organisational subunit level exit dates and to the presence of

Table 1. Diagnostic Imaging Technical Subfields

\begin{tabular}{lc}
\hline Subfield & U.S. Introduction \\
\hline Conventional x-ray imaging & 1896 \\
Nuclear medicine & 1954 \\
Ultrasound & 1957 \\
Computed tomography & 1973 \\
Magnetic resonance imaging & 1980 \\
Digital radiography & 1981 \\
\hline
\end{tabular}



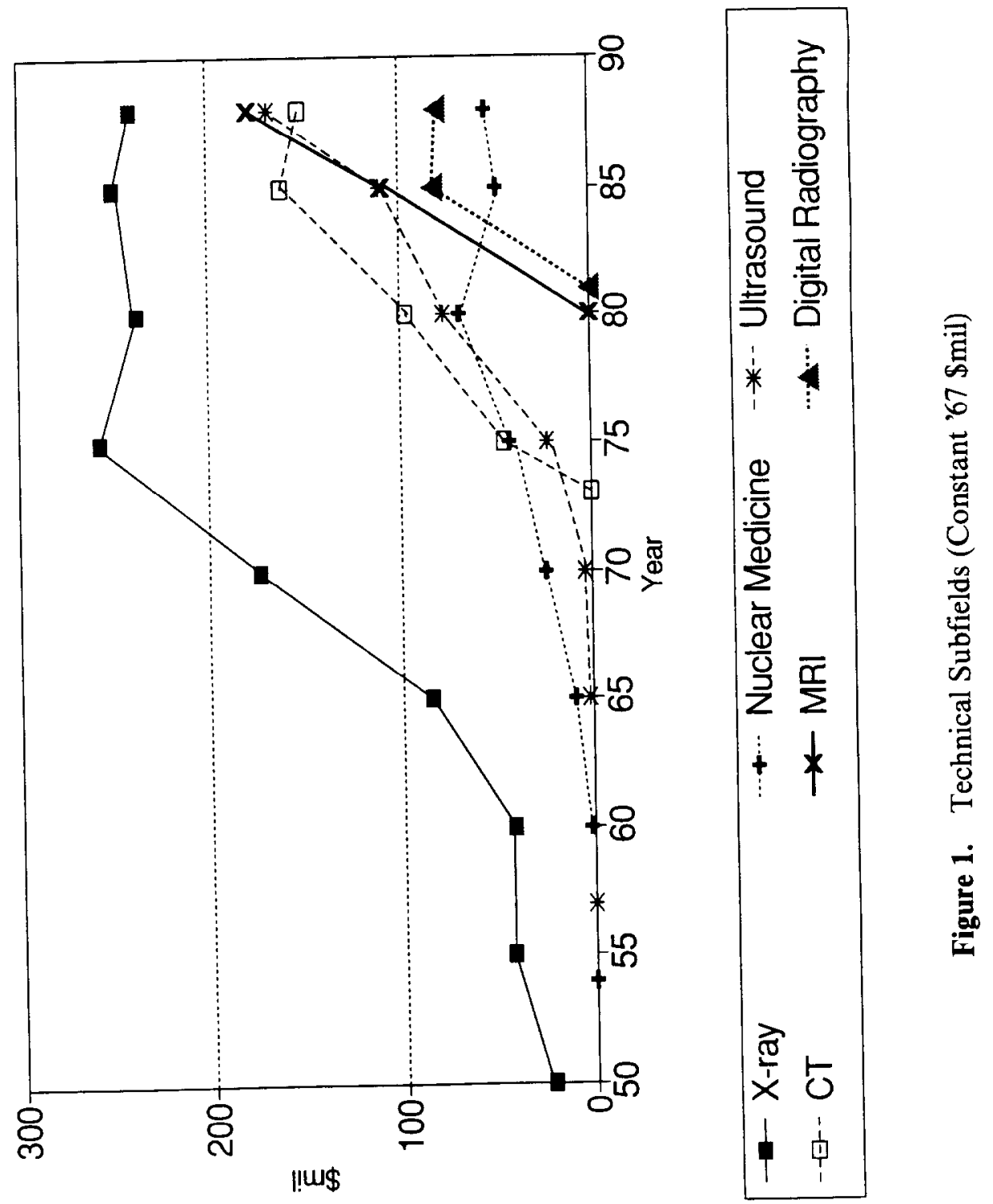
potential parent-level influences on strategy and performance. We distinguished between base subfield exit by acquisition and exit by dissolution, which have been found to reflect differing organisational and strategic influences (Freeman, Carroll \& Hannan, 1983).

The data were gathered from an extensive archival search of academic, industry, and government sources, supplemented by interviews with industry and academic participants. The sample includes all firms participating in the $\mathrm{x}$-ray, nuclear, ultrasound, CT, and magnetic resonance subfields when new subfields emerged. ${ }^{4}$ In using a data set comprising all firm in the industry, which includes firms that did not expand into the new subfields, we avoid the bias that would have resulted from only analyzing the performance of firms that actually expanded. Comparison of 14 base subfield-new subfield pairs produced 371 base subfield incumbents, 100 of which expanded into emerging subfields. By the end of the study, 187 incumbents had exited from the base subfields ( 81 by acquisition and 106 by dissolution). Analyses were carried out for the full pool of 371 incumbents. We checked for bias introduced by the pooling (Tuma \& Hannan, 1984), finding no qualitative differences.

\section{Variables}

Dependent variables. We employ two measures or performance, continued participation and subsequent market share, because previous research has demonstrated that financial and market share performance are often affected differently from survival measures (Mitchell, 1991; Haveman 1992; Mitchell \& Singh, 1993). Continued participation was measured as the number of years that a firm continued to participate in the base business after the emergence of a new subfield. ${ }^{5}$ For example, the survival of each firm participating in the $x$-ray or nuclear base subfield during 1956 (the year before the commercial introduction of diagnostic ultrasound equipment) was clocked until its exit from its base subfield. A 0-1 right-censor dummy variable identified firms participating at the end of the study. In the analysis of exit by acquisition and dissolution, we treated each type as a censored case in the analysis of the other (Freeman et al., 1983), thus allowing decomposition of the sample while maximising use of the data. When we examined influences on the length of participation before exit by dissolution we recorded firms that exited by acquisition as censored cases, for example, just as we recorded firms that continued to participate at the end of the study as censored cases.

The market share variables were arbitrarily defined as the market share in the base business held by an incumbent during years 4,8 , and 16 after the emergence of a new subfield. The 4 and 8 year measures apply to all base and emerging subfields; the 16 year market share measure does not apply to base subfield performance following emergence of the magnetic resonance and digital radiography subfields, which have not reached 16 years of existence. Only firms that survived at least 5, 9, and 17 years were included in the market share analyses.

Expansion variables. We used the following eight combinations of threeway interactions between the firms' actions (expansion or nonexpansion), firm 
types (generalist or specialist) and product types (substitute or neutral), which correspond to the noted hypotheses and research questions.

$\begin{array}{llll}\text { Hypothesis } & \text { Action } & \text { Firm-type } & \text { Product-type } \\ \text { H1a. } & \text { Expansion } & \text { Generalist } & \text { Substitute } \\ \text { H2a. } & \text { Expansion } & \text { Generalist } & \text { Neutral } \\ \text { H3a. } & \text { Expansion } & \text { Specialist } & \text { Substitute } \\ \text { RQ1a. } & \text { Expansion } & \text { Specialist } & \text { Neutral } \\ \text { H1b. } & \text { Nonexpansion } & \text { Generalist } & \text { Substitute } \\ \text { H2b. } & \text { Nonexpansion } & \text { Generalist } & \text { Neutral } \\ \text { H3b. } & \text { Nonexpansion } & \text { Specialist } & \text { Substitute } \\ \text { RQ1b. } & \text { Nonexpansion } & \text { Specialist } & \text { Neutral }\end{array}$

We used the combinations to calculate eight dummy variables. For example, we defined one dummy variable to identify generalists firms that expanded into substitute subfields (H1a). Similarly, another dummy variable identified generalists expanding into neutral subfields $(\mathbf{H} 2 \mathbf{a})$. We then employed mean effects coding to estimate comparisons against the overall average effect. ${ }^{6}$

We assigned firm type and product type status based on the following reasoning. We judged substitution to be significant for the CT new subfield with respect to the $\mathrm{x}$-ray and nuclear base subfields, and for the magnetic resonance and digital radiography new subfields with respect to the $\mathrm{x}$-ray and CT base subfields (Mitchell, 1989). As noted earlier, we defined a firm that participated in only one subfield within the diagnostic imaging industry when a new subfield emerged as a specialist, and an incumbent of more than one subficld as a gencralist.

Control variables. We defined several control variables at the firm and subfield levels. These included: (1) prior industry market share; and (2) prior base subfield market share, measured during the year before the emergence of a new subfield; (3) firm size, measured as the log value of corporate sales deflated by the Producer Price Index $(1967=1)$; (4) a missing size indicator variable, for cases in which size was estimated; (5) a U.S. majority ownership dummy variable, to control for the advantages that American firms may enjoy in the U.S. market and for systematic differences that have been found between U.S. and foreign firms in this industry (Mitchell \& Singh 1993); (6) a variable that recorded the introduction year of the relevant new subfield; and (7) a set of four mean effects base subfield dummy variables. ${ }^{7}$ The first three variables, prior industry market share, prior base subfield market share, and firm size, all measure the strength of firms prior to the expansion decision. Collectively, they control for effects that such strength may have on firms' propensity to undertake expansion.

\section{Statistical Methods}

We used accelerated event-time regression (Kalbfleisch \& Prentice, 1980; Cox \& Oakes, 1984) to estimate the effects of expansion on survival performance and conventional maximum-likelihood regression to examine the market share 
effects. We specified log-linear accelerated event-time models, selecting the logistic distribution as the baseline parametric assumption, on the basis of best data fit. ${ }^{8}$ Using the accelerated event-time method in this case permits us to incorporate the information that the length of continued participation for some firms was right-censored (Mitchell, 1991), that is, they had not exited the base subfield by the end of the study. With the conventional regression market share models, we specified linear normally-distributed models. All models were estimated with maximum likelihood procedures of the PROC LIFEREG procedure of SAS (SAS Institute, Inc., 1985).

\section{Results}

Table 2 displays the results of the tests. We first discuss the effects on the length of continued participation and next examine influences on market share. We then briefly review the firm-level and subfield-level control effects.

As predicted, most expansion effects on the length of participation were positive, while most nonexpansion effects were negative (column 1). As we expected, expansion by generalists into substitute subfields is somewhat more positive than other generalist and specialist expansion effects. The converse does not hold, however, as nonexpansion in generalist-substitute cases is no more negative than all but specialist-substitute nonexpansion. In the specialist-neutral case, which was the subject of Research Questions la and $1 \mathrm{~b}$, it appears that the positive effects of expansion and negative effects of nonexpansion overwhelm any differential product-type and firm-type effects.

Similar results are obtained when the acquisition and dissolution exits are analyzed separately. Nonexpansion is usually associated with shorter survival for both acquisition and dissolution (columns 2 and 3), as it was for all exits. The expansion-acquisition results in column 2 also are generally consistent with the magnitude of the influences on all exits, although the significance varies somewhat and the positive generalist expansion effect grows substantially. ${ }^{9}$

Although the acquisition influences are similar to the all-exit case, the expansion-dissolution results in column 3 differ strikingly. Expansion has no significant effect on generalists that shut down, whether they expand into substitute or neutral subfields. It is likely that generalists are better able to tolerate the poor performance of any particular subfield, and that they cease operations because of weakness in all their businesses rather than because of shortcomings in any single area of operation. Therefore, the negative effects of any single expansion are likely to be less severe for generalists. For specialists, meanwhile, the positive effect of expansion into neutral subfields becomes substantially stronger for dissolution exits. It appears that specialists may sometimes stave off dissolution of a problem business by expanding into a new, neutral subfield. Consistent with intuition, expansion into a substitute business does not offer the specialist firm a similar benefit.

In the market share analyses (columns 4-6), the nonexpansion influences tend to take the predicted negative direction, although the effects become more variable in the longer-term eight and 16 year estimates. There are few significant 


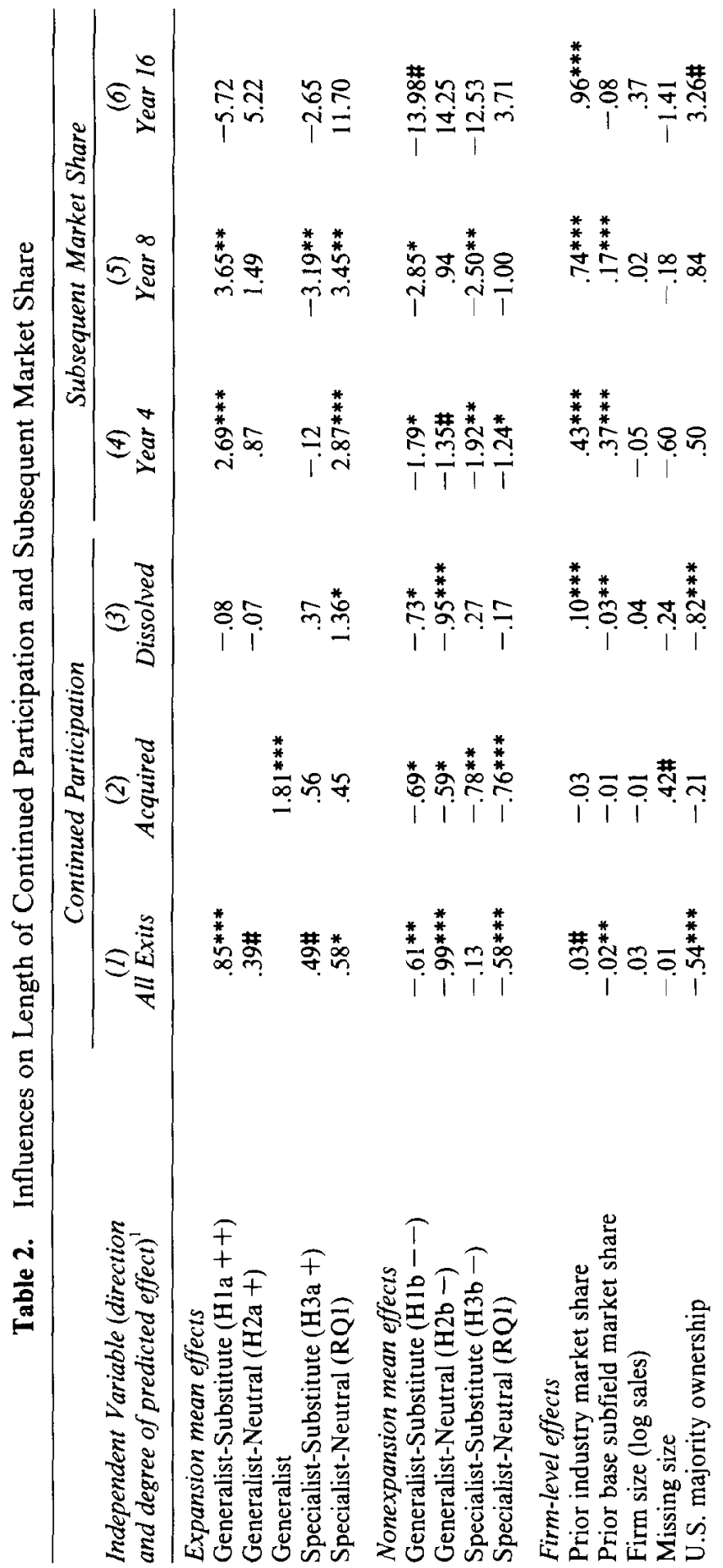




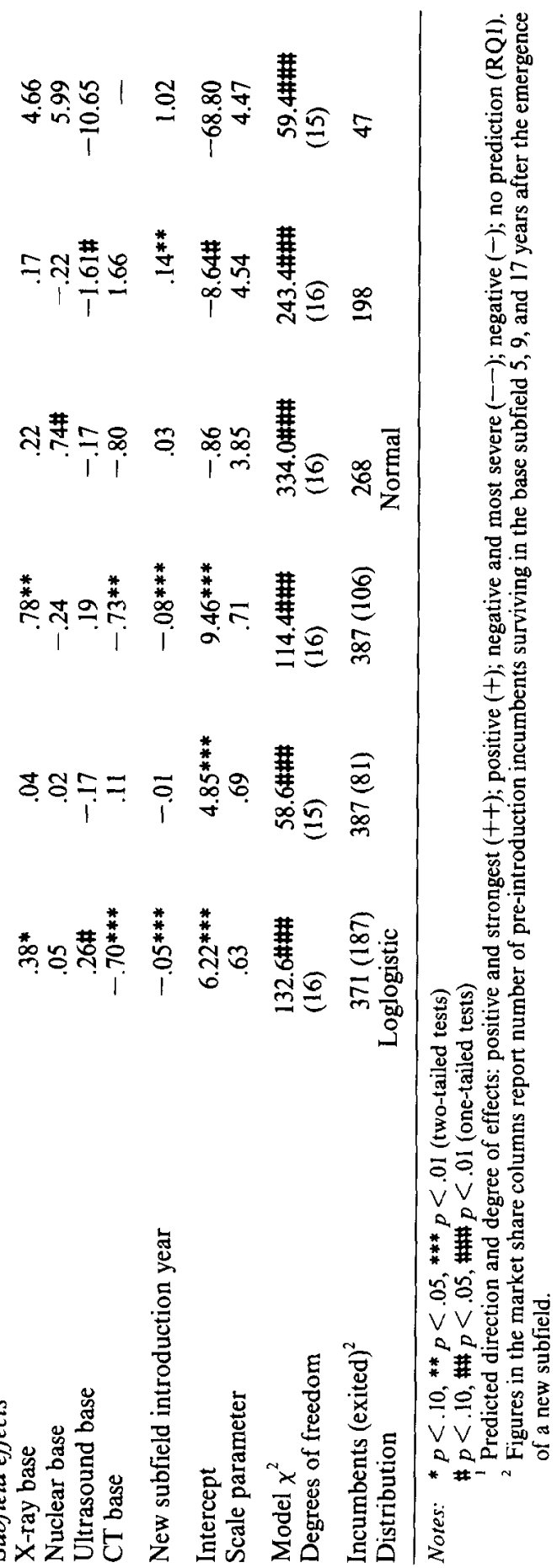


differences among firm-types and product-types in the nonexpansion cases. As expected, though, nonexpansion by specialists into neutral product areas is consistently less harmful than most other nonexpansion cases. Similarly, nonexpansion by generalists into neutral product areas has, at most, weakly negative or no significant influence on subsequent market share.

The effects of expansion on subsequent market share are more varied. As expected, generalists that expand into substitute product areas receive the greatest benefit in their base businesses, although the benefit disappears by year 16. Specialists that expand into substitute subfields, meanwhile, tend to fare relatively poorly in their base businesses. Specialists that expand into neutral subfields, though, receive strong spillback benefits. It is probable that substitute expansion causes cannibalisation and confusion on the part of a specialist's customers, while neutral expansion provides an opportunity to devclop ncw market niches without disrupting established focused operations.

In summary, we found most predicted influences of the interactions between expansion, product-type, and firm-type. Most survival and market share results supported Hypotheses $1 \mathrm{a}, 1 \mathrm{~b}$, and $2 \mathrm{~b}$. Generalists that expand into substitute subfields do better than average. Generalists that do not expand, whether into substitute or neutral subfields, do worse than average. Consistent with Hypothesis $3 b$, specialists that do not expand into substitute subfields fare poorly. The results are more mixed for Hypotheses $2 a$ and $3 a$, providing little consistent support for the propositions that expansion by generalists into neutral subfields and specialists into substitute subfields will lead to improved performance. Generally, our results strongly argue for the position that incumbents are better off facing the costs and risks of expansion than cautiously maintaining the status quo when a new industry subfield emerges.

Among the control variables, only prior industry and subfield market share had consistent effects on subsequent market share. Both influences tended to be positive, with industry share having the greatest and longest lasting pressure. The most consistent influences on survival were prior market share, U.S. ownership, and new subfield introduction year. Mitchell and Singh (1993) predicted and found the negative influence of prior subfield market share. Consistent with other studies of this and other industries (e.g., Mitchell 1989), U.S. ownership had a negative impact on base subfield survival. The control influences on survival apply almost entirely to exit by dissolution, with few significant effects emerging in the acquisition model.

\section{Discussion}

This paper addresses the key issue in the study of organisational change, which is not whether change is good or bad, but when changes will be beneficial to an organization and when they will be more likely to harm its performance (Mitchell \& Singh, 1993). As expected, spillback effects into a base business vary with the types of firms that expand and the types of new subfields into which they expand. The survival analyses supported most predictions, although the results apply most strongly to exit by acquisition and more weakly to 
dissolution exits. We found most predicted nonexpansion effects on subsequent market share, although some expansion influences on market share were counter to those expected.

Among the most interesting distinctions that arise from the analysis is the differential influence of the expansion strategy followed by specialist firms following the emergence of substitute and neutral subfields. Refer first to the specialist-substitute cases. Here, the differential effects of expansion and nonexpansion are small. Specialists that expand survive slightly longer than those that do not, at least before exiting by acquisition. Even specialists that survive receive only short-term relative market share benefits from expansion; only for year 4 market share is nonexpansion into a substitute subfield associated with significantly less market share than expansion. In general, a specialist is at risk following the emergence of a substitute subfield. Its market share tends to decline and its hopes for continued survival are, at best, average.

Notice, though, that generalists do gain market share advantages through expansion into substitute subfields. At the same time, failure to expand into these subfields has negative effects on survival and subsequent market share, suggesting that generalist must offer products in new substitutes in order to maintain the breadth of their product lines. This may occur because their broader product scope leads to more joint purchases by a single buyer of products in several technical subfields. For instance, a hospital may decide to purchase CT scanners, $\mathrm{x}$-ray equipment, and MRI instruments from a single buyer.

Next note the effects on a specialist of an expansion strategy following the emergence of a neutral subfield. This environmental change presents both a threat and an opportunity for specialist firms. Specialists that do not expand fare poorly. They tend to have shorter continued participation and, at best, only maintain their relative market share. Specialists that expand into neutral subfields, meanwhile, may realise significant spillback benefits. They achieve moderately longer survival and strikingly greater market share in their base businesses. The market share benefits, indeed, appear to be even larger than those realised by generalists that expand into neutral subfields. This last result may imply that generalist status confers declining spillback benefits. The first successful expansion from a specialist core appears to provide substantial benefit to the base business; subsequent expansions provide lesser, but still positive, advantages. This result suggests that specialists can significantly improve their performance by fundamentally realigning their strategy to offer more general product lines, as long as these do not conflict with their base operations. Indeed, this expansion path may offer a route by which specialists can become successful generalists.

These results are generally consistent with those obtained by Haveman (1992), who demonstrated that core changes are often beneficial to financial performance and survival. Haveman also found that expansions into related areas enhanced financial performance while changes into unrelated areas hurt performance. Our analysis of substitute and neutral subfields is generally similar to her employment of related and unrelated expansions, and provides 
clarification of her results. ${ }^{10}$ While expansion into substitute or related areas is beneficial, we find that expansion into neutral areas is sometimes equally beneficial. More importantly, failure to expand into new subfields can be so harmful to survival and market performance that irrespective of the degree of relatedness, or of firms' basic strategy, expansion into these new subfields is almost mandatory. Ferguson and Morris (1993) make this point quite succinctly:

The issue is not whether a company's technology will be supplanted but by whom. Companies that resist internal cannibalization will die at the hands of outsiders.

Finally, let us return to the issue that we raised in the opening discussion. Do these results suggest that firms should readily undertake changes to their core and do the results conflict with predictions that organisations changing their core activities will incur high risks of failure? A key central result of this study is that firms expanding into a new technical subfield tend to survive longer than those that do not expand. This suggests that not only can firms undertake major expansion to their core businesses, but also that they should expand under most circumstances when faced with new market opportunities. Even allowing for accompanying caveats, this result appears to contradict basic ecological predictions.

But does introducing products in a new technical subfield of an industry represent changing the core structure of an incumbent's organisation, even when the products themselves require new technology? In low-transilience cases, which is the context of this study, we suggest that expansion represents an extension of the core rather than a fundamental change of the core. During its early years in an industry, core products tend to represent a particularly significant component of a firm's strategy (Hayes \& Wheelwright, 1984; Schoonhoven, Eisenhardt \& Lyman, 1990) and consequently help define core structure. As it gains experience in the industry, however, the assets that support development and commercialisation of products arguably become more important to the firm's strategy and more integral parts of its resources and structure than any particular product. Specific products are less important to an industry incumbent than the possession of competencies that enable it to develop, sell, and service goods. An expanding firm in our study uses its established manufacturing routines to help commercialise a new product drawing on a new technical knowledge base and may require only adaptive change in its marketing function. Hannan and Freeman (1984, p. 156) identify stated goals, forms of authority, core technology and marketing strategy as the four elements that comprise an organisation's core. Consequently, while significant, the form of expansion we study may require firms to change only one element of the organisational core.

We suggest that the supporting routines are as much or more a part of the core of a firm as the specific products it sells or the markets its serves. In representing a stable set of patterns or competencies through which firms develop and commercialise their products, routines (Nelson \& Winter, 1982) 
are as central to organisations as the asset they own, the goods they produce and the personnel employ. Expansions that allow firms to continue to utilise existing routines while requiring firms to adopt new technologies may pose fewer organisational change challenges than often suspected.

Associating products with the periphery of a business and supporting systems with its core may run counter to some intuition. However, it is generally recognised that replicating supporting systems is often more costly and difficult than imitating product innovations (e.g., Lippman \& Rumelt, 1982; Teece, 1986; Mitchell, 1989). In such cases, it is the supporting systems that provide value and give a business its strength. This seems to us to be the essential nature of the core features of a business. Our argument is consistent with the notion that firms can be viewed as bundles of resources, routines and competencies, many of which are only indirectly related to the physical products marketed (Prahalad \& Hamel, 1990; Barney, 1991). This argument is also consistent with the idea that firms tend to grow through expansion of core activities into new technological and market arenas (e.g., Penrose, 1959; Thompson, 1967; Lawrence \& Lorsch, 1967; Meyer \& Scott, 1983).

Industry incumbents face significant strategic challenges when a new technical subfield of an industry emerges. Because many new products fail, many incumbents wait for the new products to prove themselves technically and in the market. If the new products succeed, most incumbents wishing to continue to participate in the industry must expand or risk exiting their base businesses. However, different types of products present different challenges to different types of firms. Broad-scope incumbents tend to face the greatest risks of nonexpansion. Single product-line firms, meanwhile, receive significant benefit from expansion into a neutral subfield but few benefits from expansion into a substitute subfield. On the other hand, failing to expand is almost uniformly detrimental. Resolving expansion issues requires understanding of the attributes of the new products, the uses to which their buyers put them, and the capabilities of the firms that might offer them. In sum, our findings clarify that the important question for firms is not how they can avoid or minimise the impact of change. Instead, the key issue is that firms have a limited choice when facing change: undertake the difficult process of expansion and possibly enjoy improved performance, or avoid expansion and face shorter survival.

Acknowledgment: An earlier version of this paper was presented at the Administrative Sciences Association of Canada meetings in Niagara Falls, June 1991.

\section{Notes}

1. We use the substitute-neutral distinction rather than the more traditional related-unrelated dichotomy, because our analysis examines low-transilience expansion. The core technology for all subfields in the medical diagnostic imaging industry was different, while supporting assets continued to be useful in all cases. Therefore the subfields were all related or all unrelated, depending on the measure of relatedness employed. Our classification provides variation on the firm-type categorisation. If relatedness is defined as the functions for which consumers utilise a product, which is a nontraditional but reasonable 
definition, then our substitute subfields can be interpreted as related and the neutral subfields as unrelated.

2. Despite representing relatively old technology, for example, dot matrix printers continue to be sold alongside newer printer technologies. Though laser, ink jet, and dot matrix printers all employ different core technologies, the same supporting assets can be used for all three product types. The consumer electronics, white good home appliance, and pharmaceutical industries are other relevant examples.

3. As in the case of substitute and neutral products, an alternate logic may apply to the generalist-specialist distinction. It is possible that all firms, whether specialists or generalists, find it difficult to expand into new businesses and to realise potential spillback benefits. If so, the firm-type distinction may not differentiate between success in the base subfield.

4. The last subfield to emerge was digital radiography in 1981 , which thus contributed no incumbents to the analysis.

5. Survival in the base business is a valid measure of performance in the medical diagnostic imaging industry, since all subfields have continued to exist with significant sales after the emergence of new subfields. Base subfield survival may be a less appropriate measure for industries in which these base subfields are eliminated or are reduced to marginal status after new subfields emerge. In these circumstances, persistence in basc subficlds may wcll reflect an inability to change, and thus, poorer performance.

6. With mean effects coding, one starts with a set of 0-1 dummy variables. A single variable is then omitted and the value of the other variables is changed from 0 to -1 for cases in which the omitted variable is equal to 1 . The resulting analysis that uses the variables compares the effect of each variable to the overall mean effect, rather than to the effect of the omitted variable as is the result of the more common dummy variable procedure. The mean effects procedure can be repeated after omitting a different variable in order to obtain a value for the variable that was omitted in the first analysis. When values are obtained for all variables in the set, the coefficients sum to 0. Mean effects coding is appropriate when the theoretical interest in the variables concerns overall directions, rather than comparison to a single influence.

7. Mitchell and Singh (1993) describe the variables, discuss expected influences, and provide summary statistics.

8. The models look the form $\ln (T)=\beta \mathrm{X}+\epsilon$, where $\ln (\mathrm{T})$ is the natural $\log$ of the length of participation $T, X$ is a matrix of explanatory variables, $b$ is an associated coefficient vector, and e is a parametrically distributed error term.

9. Only the overall generalist expansion effect is reported in the acquisition model because estimates that distinguished between expansion into substitute and neutral subfields would not converge.

10. Haveman (1992) studies the expansion of savings and loans institutions' investments from traditional residential mortgages into new commercial and non-commercial investments. On the basis of similarity of products, consumers and technology, these expansions were classified as related or unrelated. The new activities, though different from existing operations, depended "... on established routines and competencies" (Haveman, 1992, p. 49), and amounted to low-transilience changes. Therefore, Haveman's (1992) related-unrelated classification is comparable to our substitute-neutral classification. (See also footnote 1 above.)

\section{References}

Abernathy, William J. \& Clark, Kim B. (1985). Innovation: Mapping the winds of creative destruction. Research Policy, 14: 3-22.

Amit, R. (1986). Cost leadership strategy and experience curves. Strategic Management Journal, 7: $281-292$.

Barney, Jay. (1991). Firm resources and sustained competitive advantage. Journal of Management, 17(1): 99-120.

Cooper, Arnold C. \& Schendel, Dan. (1976). Strategic responses to technological threats. Business Horizons, (February): 61-69.

Cox, D.R. \& Oakes, D. (1984). Analysis of survival time data. London: Chapman \& Hall.

Cyert, Richard M. \& March, James G. (1963). A behavioral theory of the firm. Englewood Cliffs: PrenticeHall.

Delacroix, Jacques \& Swaminathan, Anand. (1991). Cosmetic, speculative, and adaptive organizational change in the wine industry: A longitudinal study. Administrative Science Quarterly, 36: 631-661.

Dosi, Giovanni. (1988). Sources, procedures and microeconomic effects on innovation. Journal of Economic Literature, 26: 1120-1230.

Ferguson, C. H. \& Morris, C. R. (1993). Computer wars: How the west can win in a post-IBM world. New York: Random House. 
Freeman, John H., Carroll, Glenn R. \& Hannan, Michael T. (1983). The liability of newness: Age dependence in organizational death rates. American Sociology Review, 48: 692-710.

Hannan, Michael T.\& Freeman, John H. (1977). The population ecology of organizations. American Journal of Sociology, 82: 929-964.

(1984). Structural inertia and organization change. American Sociological Review, 49: 149-164. (1989). Organisational ecology. Cambridge: Harvard University Press.

Haveman, Heather A. (1992). Between a rock and a hard place: Organisational change and failure under conditions of fundamental environmental transformation. Administrative Science Quarterly, 37: 4875 .

Hayes, Robert H. \& Wheelwright, Steven C. (1984). Restoring our competitive edge: Competing through manufacturing. New York: John Wiley \& Sons.

Kalbfleisch, J. D. \& Prentice, R. L. (1980). The statistical analysis of failure time data. New York: John Wiley \& Sons.

Kelly, Dawn \& Amburgey, Terry L. (1989). A test of organizational inertia theory. Paper presented at the annual meetings of the Academy of Management, Washington, D.C.

Lawrence, Paul R. \& Lorsch, Jay W. (1967). Organization and environment: Managing differentiation and integration. Boston: Graduate School of Business Administration, Harvard University.

Leibenstein, Harvey. (1966). Allocative efficiency v. X-inefficiency. American Economic Review, 56: 392415.

Lippman, S. A. \& Rumclt, R. P. (1982). Uncertain imitability: An analysis of interfirm differences in efficiency under competition. Bell Journal of Economics, 13: 418-438.

Meyer, John \& Scott, W. Richard. (1983). Organizational environments: Ritual and rationality. Beverly Hills: Sage.

Miner, Anne S., Amburgey, Terry L. \& Stearns, Timothy. (1989). Partial selection in organizational populations. Paper presented at the annual meetings of the Academy of Management, Washington, D.C.

Mitchell, Will. (1989). Whether and when? Probability and timing of incumbents' entry into emerging industrial subfields. Administrative Science Quarterly, 34E: 208-230.

. [1991]. Dual clocks: Entry order influences on industry incumbent and newcomer market share and survival when specialized assets retain their value. Strategic Management Journal, (February): 12, 85-100.

Mitchell, Will \& Singh, Kulwant. (1993). Death of the lethargic: Effects of expansion into new technical subfields of an industry on performance in a firm's base business. Organization Science, (forthcoming).

Nelson, Richard R. (1959). The simple economics of basic scientific rescarch. Quarterly Journal of Economics, 74: 297-306.

Nelson, Richard R. \& Winter, Sydney G. (1982). An evolutionary theory of economic change. Cambridge, MA: Harvard University Press.

Penrose, Edith. (1959). The theory of the growth of the firm. New York: Wiley.

Porter, Michael E. (1980). Competitive strategy. New York: The Free Press.

Prahalad, C. K. \& Hamel, Gary. (1990). The core competence of the corporation. Harvard Business Review, (May-June): 79-91.

Reinganum, Jennifer F. (1983). Uncertain innovation and the persistence of monopoly. American Economic Review, 73: 741-748.

SAS Institute Inc. (1985). SAS user's guide: Statistics, Version 6 ed. Cary, NC: SAS Institute Inc.

Schoonhoven, Claudia B., Eisenhardt, Kathleen M. \& Lyman, Katherine. (1990). Speeding products to market: Waiting time to first product introduction in new firms. Administrative Science Quarterly, 35: 177-207.

Shelton, John P. (1967). Allocative efficiency v. 'X-efficiency': Comment. American Economic Review, 57: 1252-1258.

Singh, Jitendra V., House, Robert J. \& Tucker, David J. (1986). Organizational change and organizational mortality. Administrative Science Quarterly, 31: 587-611.

Teece, David J. (1980). Economies of scope and the scope of the enterprise. Journal Of Economic Behavior And Organization, 1: 223-247.

. (1986). Profiting from technological innovation: Implications for integration, collaboration, liccnsing, and public policy. Research Policy, 15: 285-305.

Thompson, James. (1967). Organizations in action. New York: McGraw-Hill.

Tuma, Nancy B. \& Hannan, Michael T. (1984). Social dynamics: Models and methods. Orlando, FL: Academic Press, Inc.

United States Supreme Court. (1964). Brown Shoe Co., v. United States, 370 U.S., 294. 
Wheelwright, S. C. (1985). Restoring competitiveness in U.S. manufacturing. California Management Review, 27(3): 26-42.

Zajac, Edward J. \& Shortell, Stephen M. (1989). Changing generic strategies: Likelihood, direction, and performance implications. Strategic Management Journal, 10: 413-430. 